\title{
EUGENIO BULYGIN: UN ANÁLISIS (NO) FILOSÓFICO
}

\author{
Alejandro D. Calzetta ${ }^{a}$ \\ https://orcid.org/0000-0003-2852-6947 \\ acalzetta@uahurtado.cl \\ Julieta A. RABANos ${ }^{b}$ \\ https://orcid.org/0000-0003-0490-3779 \\ julieta.rabanos@giuri.unige.it \\ ${ }^{a}$ Universidad Alberto Hurtado, Santiago de Chile, Chile \\ ${ }^{b}$ Università degli Studi di Genova, Génova, Italia
}

Cuando pensamos en Eugenio, especialmente al momento de intentar escribir estas palabras, su recuerdo es para nosotros un poco como lo fue él mismo: inmenso, inconmensurable, inagotable. Nuestra memoria está llena hasta el tope de anécdotas, sensaciones, agradecimientos y perplejidades, al punto que dejar salir a algunos de ellos en algún orden inteligible se vuelve una epopeya. Quizás usando algo similar al método de la reconstrucción racional, que hemos aprendido de él, podamos llevar adelante el intento; confiando además en que los aspectos de su realidad que aquí quedarán afuera serán, a su vez, captados y reproducidos por otros (Alchourrón \& Bulygin, 2012, p. $13-14 ; 1971$, p. 9).

Eugenio puede ser definido o, mejor aún, descrito a través de un cúmulo de propiedades independientemente positivas, y conjuntamente extraordinarias. Algunas de ellas, sin ánimo de taxatividad: una mente brillante; un sentido del humor agudo; una elegancia innata. Una habilidad infinita para transmitir conocimiento, incluso las ideas más complejas. Una generosidad inmensa en otorgar su tiempo y su dedicación, incluso (y, quizás, sobre todo) para con jóvenes bamboleándose en sus primeros pasos. Una fuerte convicción acerca de la virtud del conocimiento compartido, cristalizada en su indisociable dúo intelectual con Carlos Alchourrón. Un respeto pulido y sistemático por toda idea 0 teoría ajena, aunque la creyera totalmente equivocada, salvo aquellas que le resultaran moralmente aberrantes. Una capacidad enorme para separar (e insistir en la separación de) teoría y doctrina, ciencia e ideología, y aun así ser un intelectual política, moral y personalmente comprometido. La nada despreciable propiedad de considerar a la actividad filosófica como algo, si bien serio e importante, por demás entretenido; una actividad en la cual uno puede pasarla bien y divertirse, 
a pesar de estar uno formalizando normas y sistemas normativos. A todas estas sigue un largo etcétera que, por cuestiones de espacio, no vamos a intentar enumerar.

Nosotros lo conocimos cuando ya habían pasado tantas de las cosas que transformaron a Eugenio en, justamente, Eugenio. Llegamos tarde; tal vez fuimos, en este sentido, los últimos. Era tan ciudadano de la Argentina como cualquier otro y, a la vez, era claramente un ciudadano del mundo. En los primeros años de conocerlo ninguno de nosotros imaginaba, al menos con tanto detalle, la larga odisea de persecución que lo trajo desde la Ucrania que lo vio nacer a la rivera del Río de la Plata. Su afabilidad y lo férreo de su carácter hacían que pareciera imposible que sus inicios estuvieran signados por el terror, la persecución, la guerra, la pérdida y el desarraigo (solo con los años, y con la madurez, nos daríamos cuenta de que entre una cosa y la otra existía una relación entre efecto y causa). Sí podíamos intuir un largo kilometraje acarreado en pequeñas cosas: su facilidad para hablar idiomas, ese acento particular que prima facie resultaba inexplicable y de origen incierto, su voz profunda, y la cantidad de anécdotas variopintas cuyos protagonistas tenían nombres de un sinfín de proveniencias (solo luego nos daríamos cuenta de que muchos de esos nombres eran, o serían, aquellos que nuestra generación estudió como "clásicos").

De ese mismo modo, y a pesar de su semblante lejano de las ínfulas y con los pies en la tierra, en otras pequeñas cosas podíamos intuir el importante rol que había ocupado en nuestra comunidad académica y nacional: una fotografía suya junto con los decanos de la Facultad de Derecho de la Universidad de Buenos Aires con el epígrafe "1984-1986", su nombre figurante entre los fundadores de SADAF, un capítulo lleno de menciones a su persona en el manual de lectura obligada para generaciones enteras de teoría del derecho, un intento de refutación (infructuoso) de su teoría sobre la letra de cambio en un tratado de Derecho Comercial, menciones al pasar a su presidencia de la "asociación mundial" de filosofía del derecho (sic), etc.

Pertenecemos a una generación que conoció a Eugenio solo en las últimas décadas de su larga vida, aunque ello haya sido más que suficiente para dejar una marca indeleble en la vida de ambos. Nuestros primeros contactos con él fueron diferentes y en diferentes tiempos, aunque con la misma juventud: uno lo conoció como profesor de la materia "Sistemas Normativos" del Ciclo Profesional Orientado de la carrera de Derecho de la U.B.A. en $2003^{1}$; la otra, como director

${ }^{1}$ La materia en cuestión era de normas más fiel al trabajo de Eugenio que el ANÁLISIS FILOSÓFICO 4 I (2) - (noviembre 202I) 
del Seminario Permanente de Lógica de Normas y Teoría General del Derecho en 2009. Sin embargo, ambos tuvimos la misma sensación: haber tenido un encuentro inexplicable, inesperado, con alguien que no podría sino ser una figura irremplazable y quizás irrepetible de la vida de cada uno. Una sensación que alcanzó un grado de certeza absoluto (de aquellos desconocidos para la ciencia) en los años que siguieron, acumulando congresos (los de Bahía Blanca, los de Vaquerías, los I.V.R.s, innumerables otros...), sesiones de Seminario Permanente (todos los martes en las noches) y viajes (Córdoba, Barcelona, Madrid, San Petersburgo, Washington, Lisboa, y la lista sigue).

Somos quienes somos y hacemos lo que hacemos en parte gracias a, y a causa de, Eugenio. Ambos fuimos aceptados en nuestros respectivos estudios de posgrado con una recomendación suya. Ambos hemos escrito tesis que, con sus más y sus menos, a la larga pueden ser leídas como odas al tipo de filosofía y aproximación al análisis y conocimiento del derecho y del mundo que Eugenio propugnaba. Nuestras intuiciones filosóficas son muy cercanas a prácticamente todas las que Eugenio ha propuesto. Ambos nos aproximamos a la enseñanza siguiendo aquella máxima suya de que "la mejor manera de aprender es dar una clase, porque ahí uno se da cuenta de todo lo que no sabe" (citado en Ferrajoli Karamanian, Monti \& Rabanos, 2014). Ambos consideramos que, en la academia, la forma más sincera de halago no son los elogios ni la imitación, sino la crítica (mientras más dura, mayor el halago: "de lo contrario, parece que uno no se toma en serio aquello que critica", Eugenio dixit). Quizás divergimos en aquel último gran aprendizaje que hemos recibido de él para la academia y la vida: si bien una sigue al pie de la letra el que hay que ser suave en las formas pero firme en el mensaje, el otro piensa que hay que ser firme (muy firme) tanto en las unas como en el otro.

Intentando encontrar las palabras para continuar, lo que nos viene en realidad son recuerdos entremezclados de nuestras vivencias académicas y personales con Eugenio. Los años y años tratándolo alternativamente de "usted" y de "vos" sin solución de continuidad (aunque él insistía, impertérrito, en que no era tan viejo como para lo primero); el abrazo sobre aquel escenario al recibir de sus manos un diploma; las copas y copas de vino que nunca quedaban vacías en su presencia; la degustación de vodka que para nosotros era todo lo mismo, pero que él distinguía con rigurosidad científica; escucharle hablar ruso estando en Rusia y ser confundidos por su familia; la mirada penetrante

nombre que la monografía Normative Systems había recibido en castellano.

ANÁLISIS FILOSÓFICO 4I(2) - (noviembre 202I) 
llena de paciencia, curiosidad y atención indivisa escuchando nuestros primeros balbuceos acerca de la filosofía del derecho; la atención con la que él escuchaba una presentación de los resultados de la tesis doctoral de uno de nosotros; y muchísimas cosas más que nos es imposible separar completamente entre lo personal y lo académico.

Eugenio fue para nosotros una presencia mucho más fuerte y más central que un mero mentor. Era una constante fuente de inspiración y de apoyo, ya sea directo (mediante consejos, comentarios, charlas y un largo etcétera) o indirecto (mediante la lectura, comentarios de terceros, anécdotas, bromas). Su ausencia es algo tremendo, que se siente y se va a sentir de aquí a lo que quede de nosotros; y cada vez que hagamos algo, escribamos algo y pensemos algo en lo nuestro nos seguiremos preguntando qué es lo que Eugenio pensaría, qué comentarios y qué críticas haría, qué consejos nos daría, qué anécdota tendría para contar.

Eugenio se fue el 11 de mayo de 2021. Ambos tuvimos la fortuna de conocerlo un par de décadas. Tal vez eso nos ayude un poco, aunque lógicamente su recuerdo no podrá reemplazar nunca su presencia. Pero deberemos conformarnos con ello y seguir haciendo conocer a Eugenio por descripción, al menos a este Eugenio que nosotros conocimos, y tratar de no decepcionar con vidas e ideas lindas (pero totalmente equivocadas) su memoria.

\section{Bibliografía}

Alchourrón, C., \& Bulygin, E. (1971). Normative Systems. Springer. Alchourrón, C., \& Bulygin, E. (2012), Sistemas Normativos: Introducción a la metodología de las ciencias jurídicas (2 ed.). Astrea.

Ferrajoli Karamanian, G., Monti, E., \& Rabanos, J. (2014). Una universidad para la democracia: Entrevista a Eugenio Bulygin. Carrera y Formación Docente: Revista Digital, 3(4). http://www. derecho.uba.ar/academica/centro-desarrollo-docente/revista/ revista-N04-2014-Otono.pdf

Recibido el 12 de octubre de 2021; aceptado el 13 de octubre de 2021. 